\title{
Retórica jornalística, relato de crimes e práticas de perfilamento racial: dois casos envolvendo brasileiros
}

Journalism rhetoric, crime reports and racial profiling practices: two cases involving brazilians

\begin{abstract}
JULIANA SANTOS BOTELHO
Doutoranda em Comunicação pela Université du Québec à Montréal, onde também lecionou a disciplina "Mídia, imigração e comunidades étnicas". Sua tese de doutorado aborda o debate público gerado por publicidades denunciadas por discriminação racial no Brasil, entre 1979 e 2005.julianasbotelho@hotmail.com
\end{abstract}

\section{Resumo}

Este artigo aborda o problema das práticas de perfilamento racial tal como empregado pelas forças policiais no Brasil e na Inglaterra. Nos últimos anos, este método altamente controverso resultou na morte de duas vítimas brasileiras inocentes: Jean Charles de Menezes e Flavio Ferreira Sant'Ana. Como ambos os casos foram alvo de intensa cobertura midiática no Brasil, acreditamos que uma análise comparativa de mídia possa fornecer pistas valiosas para compreender a forma pela qual crimes resultantes de procedimentos racistas reclamam estratégias específicas de enunciação na mídia. Meu principal argumento é de que estes dois fatos - bem como as correspondentes reações públicas dos brasileiros no Brasil e no exterior - expressaram: 1) o problema de incerteza inerente a qualquer sistema de perfilamento racial, especialmente em contextos multiculturais; 2) reaçōes populares e reivindicaçōes de justiça altamente contrastantes.

Palavras-chave: análise de media, perfilamento racial, visibilidade, reflexividade, relatos criminais.

\section{A polêmica da política de "atirar para matar" e as práticas de perfilamento racial}

Muito tem-se discutido sobre a política de "atirar para matar" da Scotland Yard, mas muito pouca atenção tem sido dada ao fato de que esta política esteja fundamentada na habilidade de uma dada pessoa identificar o perfil étnico ou racial de outra.

Neste artigo, examinarei dois casos em que brasileiros foram mortos por engano por forças militares. $\mathrm{O}$ primeiro caso, que aconteceu no dia 22 de julho de 2005 na cidade de Londres, envolveu um ataque policial contra um suspeito de homem-bomba no metrô da cidade, levando à morte Jean Charles de Menezes. O segundo caso, acontecido no dia 03 de fevereiro de 2004, na cidade de São Paulo, revela práticas racistas oficiosas que vem sendo constantemente empregadas pela polícia brasileira. Tais procedimentos resultaram na morte de Flávio Ferreira Sant'Ana.

$\mathrm{O}$ que essas duas vítimas têm em comum? Além de serem ambos cidadãos brasileiros, eles também foram vítimas do emprego de um quadro de referências visuais altamente marcado pelo preconceito, cujo objetivo era de associar uma "evidência visual" a um "comportamento suspeito". No primeiro caso, Jean Charles, um eletricista de 27 anos, foi confundido com um kamikase islâmico. No segundo caso, Flávio Sant'Ana, um dentista negro de 28 anos, foi confundido com o assaltante de uma mercearia. Em ambos os casos, as circunstâncias nas quais os tiros da polícia foram disparados permaneceram abertas à controvérsia, levantando sérias dúvidas sobre a confiabilidade das versões policiais oficiais correspondentes. Além disso, ambos os fatos estavam sendo transmitidos 
"SCOTLAND Yard identifie deux suspects" Radio Canada. Montreal, jul./2005. Disponível em: < http://radio-canada.ca/nouvelles/acces/suite.asp?lien $=$ /nouvelles/ International/nouvelles/200507/24/001Londres-Ordre-Tuer.shtml>. Acesso em: 24 jul. 2005. pela mídia brasileira quase simultaneamente, uma vez que o julgamento dos assassinos de Flávio Sant'Ana tinha sido inicialmente previsto para o início do mês de agosto de 2005, isto é, poucos dias após a morte de Jean Charles.

Além de expor à apreciação pública práticas correntes de perfilamento etno-racial por forças policiais em diferentes países, tais casos nos auxiliam a colocar em questão os quadros de referência visuais que são acionados cotidianamente na vida de toda sociedade multicultural. Nestes dois casos envolvendo brasileiros, as forças policiais foram chamadas a prestar explicações públicas, oferecendo respostas que variaram entre uma "falha humana", numa situação em que se atirava "para matar", como no primeiro caso, e um ato "em legítima defesa", como no segundo. No caso de Jean Charles, os disparos rapidamente despertaram protestos públicos de indignação e de orgulho nacional. No caso de Flávio Sant'Ana, apesar de seu caso ter sido exposto a intensa cobertura mediática, sua permanência na ordem do dia se deve principalmente à ação de grupos de direitos humanos e outros movimentos envolvidos na luta contra a discriminação racial.

Meu principal argumento é o de que estes dois fatos - bem como as correspondentes reações públicas dos brasileiros no Brasil e no exterior - expressaram:

1. o problema de incerteza inerente a qualquer sistema de perfilamento racial, especialmente em contextos multiculturais;

2. reações populares e reivindicações de justiça altamente contrastantes.

Vale ainda lembrar que o recorte temporal deste trabalho privilegia as notícias veiculadas entre fevereiro de 2004, quando Flávio Sant'Ana foi assassinado, e os primeiros 30 dias que se seguirão ao assassinato de Jean Charles, em julho de 2005. Uma análise global de alguns procedimentos mediáticos utilizados nas coberturas de ambos os casos poderá nos fornecer pistas valiosas para compreender algumas motivações do debate racial brasileiro em andamento.

\section{Prestando testemunho}

As narrativas da mídia, veiculadas no Brasil e em outros países, têm fornecido aos telespectadores e ouvintes diversos detalhes de como uma "evidência visual" levou os policiais a reagirem abruptamente da forma como o fizeram. Tais narrativas sugerem possíveis interpretaçôes sobre as formas pelas quais esta evidência estava associada a um suposto "comportamento suspeito".

Passemos então ao que os jornais da época trataram como sendo a versão oficial da polícia na ocasião da morte de Jean Charles. De acordo com uma declaração oficial divulgada pela Rádio Canada dois dias após o incidente, Jean Charles, um eletricista de 27 anos,

“...deixou sua casa em Tulse Hill, que havia sido colocada sob vigilancia como parte do enquérito sobre os atentados frustrados no dia 21 de julho. Ele foi seguido por policiais à paisana até a estação de metrô Stockwell, onde foi abatido após ter tropeçado quando tentava alcançar o metrô. No momento em que recebeu os tiros, ele estava caído no chão". ${ }^{1}$

Entretanto, este relato "objetivo" e "imparcial" esconde uma grande parte da controvérsia sobre as circunstâncias nas quais a vítima foi executada. Além disso, ele diz muito pouco sobre a apa- 
rência e a atitude da vítima antes de ser abordada pelas forças policiais, ou mesmo o porquê de ele ter sido identificado como suspeito. Dado que raramente as forças policiais relatam sua própria percepção do que foi considerado como sendo um "comportamento suspeito" diretamente à mídia, muito do que se soube acerca do incidente e do comportamento "suspeito" não estava presente nas declarações oficiais da polícia mas, sim, naquilo que pôde ser inferido dos relatos das testemunhas oculares.

No caso de Jean Charles, vários testemunhos de pessoas que supostamente estiveram face-à-face com a vítima foram colocados em circulação pela agência Reuters de notícia, sendo largamente difundidas em outras partes do mundo como, por exemplo, pela TV Sky News (Inglaterra), pelo Jornal Le Devoir (Quebec) e pela Folha de São Paulo (Brasil) no dia seguinte ao acidente. Uma das testemunhas, Mark Whitby, "que estava sentado na estação de metrô Stockwell no momento em que o homem correu para o vagão", ${ }^{2}$ descreve Jean Charles de Menezes como sendo "um cara asiático", 3 que "parecia paquistanês"4 e que estaria usando um boné de beisebol e um casaco grosso. $\mathrm{O}$ Sr. Whitby, que disse que Jean Charles estava distante "a não mais de cinco jardas"s (isto é, a menos de 5 metros) de onde ele estava sentado - e que, no dia 24 de julho, lançou um confiante "vi com seus seus próprios olhos" " à rede de TV Sky News - afirmou que Jean Charles era "um cara bastante alto, corpulento, do tipo bem roliço"?

As mesmas origens asiáticas foram afirmadas por uma outra testemunha, Teri Godly, que também estava no vagão quando Jean Charles entrou no metrô. De acordo com Godly, ele parecia "um asiático alto, de barba e mochila nas costas". ${ }^{8}$ Uma outra testemunha, Anthony Larkin, contou à BBC de Londres que Jean Charles estava usando "uma cinta-bomba com fios saindo para fora", enquanto Vivian Figueiredo, prima da vítima, argumentava que a Polícia Metropolitana lhe havia dito que Jean Charles estava vestindo uma jaqueta jeans. ${ }^{9}$ Vale a pena registrar que todos estes testemunhos foram parcial ou totalmente questionados mais tarde em diversas mídias impressas.

Além disso, no que se refere especificamente à aparência física de Jean Charles, parece haver uma divergência fora do normal entre as percepções captadas à partir das testemunhas oculares e as próprias declarações da polícia. Apesar dele ter sido principalmente percebido, por algumas testemunhas, como alguém de "origem asiática", um relatório completo sobre o caso de Jean Charles de Menezes, publicado pela Wikipédia - um projeto de enciclopédia virtual de livre acesso e cuja redação é feita coletivamente por diversos especialistas -, consultado menos de um mês após o evento, argumentava, naquela ocasião, que os policiais envolvidos nos disparos "estavam vigiando três homens de aparência supostamente somaliana ou etíope". ${ }^{10}$ Estes, por sua vez, estariam diretamente implicados na tentativa frustrada de um ataque-bomba no dia anterior aos disparos que mataram Jean Charles.

Mas a controvérsia não se aplica somente à aparência de Jean Charles, mas também àquilo que foi percebido como sendo um "comportamento suspeito". De acordo com uma declaração da polícia publicada pela $\mathrm{BBC}^{11}$ no dia seguinte aos disparos, Jean Charles estava correndo e não teria parado diante da intervenção da polícia. No entanto, o primo da vítima, Alex Aleves Pereira, de 27 anos, questionou veementemente a versão oficial dos fatos, explicando à $\mathrm{BBC}$ que ele acreditava que a morte de seu primo "fora o resultado da incompetência da polícia". ${ }^{12}$ "Por
"BOMBER looked petrified" Sky News TV. Londres, jul./2005. Disponível em <http://wwww.sky.com/skynews/article/ 00,,30000'13391824,00.htm >. Acesso em: 23 jul. 2005.

3 "JEAN Charles de Menezes" Wikipedia: a enciclopédia livre. Ago./2005. Disponível em: <http://en.wikipedia.org/wiki/Jean_Charles_de_Menezes \#Controversy over_police_procedure $>$. Acesso em: $1 \overline{5}$ ago. 2005

STOCK, Adriana; GARCEZ, Bruno. "Brasileiro morto estava com visto vencido, diz governo" BBC News. Londres, jul./2005. Disponível em: <http://www.bbc. co.uk/ portuguese/reporterbbc/atory/2005/ 07/050723-alexricardoml.shtml>. Acesso em: 25 jul. 2005.

5 "JEAN Charles de Menezes" Wikipedia: a enciclopédia livre. Ago./2005. Disponível em: <http://en.wikipedia.org/wiki/Jean_Charles_de_Menezes \#Controversy over_police_procedure $>$. Acesso em: $1 \overline{5}$ ago. 2005.

6 BETTENCOUT, Babeth. "Morte de eletricista divide brasileiros em Londres" $B B C$ News. Londres, jul./2005. Disponível em: $<$ http://www.bbc.co.uk/portuguese/reporterbbc/story/2005/07/050723-reacaocomunidade.shtml>. Acesso em: 23 jul. 2005

7 "JEAN Charles de Menezes" Wikipedia: a enciclopédia livre. Ago./2005. Disponível em: <http://en.wikipedia.org/wiki/Jean_Charles_de_Menezes \#Controversy over_police_procedure $>$. Acesso em: $1 \overline{5}$ ago. 2005.

8 "BOMBER looked petrified" Sky News TV. Londres, jul./2005. Disponível em <http://wwww.sky.com/skynews/article/ 0,,30000'13391824,00.htm > . Acesso em: 23 jul. 2005

9 "JEAN Charles de Menezes" Wikipedia: a enciclopédia livre. Ago./2005. Disponível em: < http://en.wikipedia.org/wiki/Jean_Charles_de_Menezes \#Controversy over_police_procedure $>$. Acesso em: $1 \overline{5}$ ago. 2005 .

10 "JEAN Charles de Menezes" Wikipedia: a enciclopédia livre. Ago./2005. Disponível em: < http://en.wikipedia.org/wiki/Jean_Charles_de_Menezes \#Controversy over police procedure $>$. Acesso em: 15 ago. 2005.

11 BETTENCOUT, Babeth. "Morte de eletricista divide brasileiros em Londres" $B B C$ News. Londres, jul./2005. Disponível em: $<$ http://www.bbc.co.uk/portuguese/reporterbbc/story/2005/07/050723-reacaocomunidade.shtml>. Acesso em: 23 jul. 2005.

12 Idem. 
13 "JEAN Charles de Menezes" Wikipedia: a enciclopédia livre. Ago./2005. Disponível em: <http://en.wikipedia.org/wiki/Jean_Charles_de_Menezes \#Controversy over_police_procedure $>$. Acesso em: $1 \overline{5}$ ago. 2005.

14 Idem.

15 Ibidem.

16 "BLAIR discute mudança na lei antiterrorismo com oposição brintânica" $B B C$ News. Londres, jul./2005. Diponível em: $<$ http://www.bbc.co.uk/portuguese/noticias/story/2005/07/050726-blairmeetsfn. shtml>. Acesso em: 26 jul. 2005.

17 "JEAN Charles de Menezes" Wikipedia: a enciclopédia livre. Ago./2005. Disponível em: <http://en.wikipedia.org/wiki/Jean_Charles_de_Menezes\#Controversy over_police_procedure $>$. Acesso em: $1 \overline{5}$ ago. 2005.

18 "BLAIR discute mudança na lei antiterrorismo com oposição brintânica" BBC News. Londres, jul./2005. Diponível em: $<$ http://www.bbc.co.uk/portuguese/noticias/story/2005/07/050726-blairmeetsfn. shtml> . Acesso em: 26 jul. 2005.

19 MARTINS, Silvia Helena. "Racismo e violência" Mundo Negro: 0 maior portal da comunidade afro-brasileira. Ago./2005. Disponível em: <http://www.mundonegro. com.br/noticias/index.php?noticialD = 265>. Acesso em: 15 ago. 2005.

20 "COMANDANTE diz que versão de PMs sobre morte de dentista é falsa" Folha Online. São Paulo, jul./2005. Disponível em: $<$ http://www1.folha.uol.com.br/folha/cotidiano/ult95u89837.shtml>. Acesso em: 27 jul. 2005.

${ }^{21}$ /dem

22 Ibidem. que eles o deixaram entrar em um ônibus se temiam homens-bomba?... Ele podia estar correndo, mas não da polícia. Quando o [ônibus] Underground pára, todo mundo corre para pegar o trem. O fato de que ele tenha saltado as barreiras é mentira". ${ }^{13}$ Ainda de acordo com o mesmo relatório disponível na Wikipédia, "a polícia havia recusado a divulgação da cenas da câmera da CCTV, até mesmo para a família". ${ }^{14}$ Contudo, uma teoria avançada pelo Jornal The Scotsman poucos dias após o incidente sugere que quem as testemunhas disseram ter visto saltando a catraca do metrô teria sido, na verdade, um dos policiais que o perseguia. ${ }^{15}$

A maneira pela qual Jean Charles de Menezes foi morto foi também um outro tema de discussão. Testemunhas oculares afirmaram que Jean Charles havia recebido cinco tiros, ao passo que os relatórios oficiais admitiram mais tarde que ele tinha, de fato, recebido oito tiros. ${ }^{16}$ Sob este aspecto, o próprio primo de Jean Charles, Alex Pereira, acabou se tornando uma testemunha ocular. Ele disse: "Eu me precipitei para dentro da câmera mortuária. Sua boca estava distorcida pelos machucados e parecia que ele havia sido atingido pela nuca". ${ }^{17}$ De qualquer forma, o comissário da Polícia Metropolitana, Sr. Ian Blair, afirmou numa entrevista coletiva, passados quatro dias do incidente, que uma advertência verbal havia sido proferida antes dos tiros, que a abordagem de atirar para matar era destinada à proteção de todos e que ela estava ainda em vigor. ${ }^{18}$

Passemos agora ao nosso segundo caso, a morte de Flávio Ferreira Sant'Ana. A primeira declaração oficial da polícia dizia que Flávio Sant'Ana, um dentista de 28 anos, foi abordado por dois policiais a caminho de casa. Flávio estava dirigindo um carro em Higienópolis, seu próprio bairro, na cidade de São Paulo. Após ter sido identificado como o assaltante de uma mercearia próxima dali, a vítima resistiu aos policiais e tentou atirar. Estes reagiram e atiraram duas vezes no peito do jovem dentista. A carteira do proprietário da mercearia foi encontrada em um dos bolsos da calça de Flávio. ${ }^{19}$

Contrariamente ao caso de Jean Charles de Menezes, os disparos contra Flávio Sant'Ana não foram presenciados por testemunhas oculares, capazes de colocar em xeque a versão sugerida pela declaração em questão. Contudo, a versão inicial foi questionada poucos dias depois por meio de uma testemunha indireta, Antônio dos Anjos, de 29 anos, o próprio proprietário da mercearia. Ele negou que a afirmação da polícia, segundo a qual ele mesmo teria reconhecido Sant'Ana como sendo o verdadeiro assaltante.

Por falta de veracidade, a versão da polícia - segundo a qual um dentista teria roubado uma mercearia caiu definitivamente por terra sete dias após os disparos, fruto do apelo de nada mais nada menos que o então Comandante Geral de Polícia Militar de São Paulo, coronel Alberto Silveira Rodrigues. Em uma entrevista veiculada no dia 10 de fevereiro de 2004 no Jornal Folha de São Paulo, ${ }^{20}$ Rodrigues afirmou que, diante de revelações mais recentes, a versão dos fatos aventada pelos policiais não era verdadeira, já que "a confissão de um deles aponta que uma carteira foi colocada no bolso, posteriormente". ${ }^{21} \mathrm{E}$ acrescenta: "Em nenhum instante seremos cúmplices da ação de maus policiais" 22 . Esta declaração bombástica foi feita logo após uma visita do comandante ao pai da vítima, o Sr. Jonas Sant’Ana, que é ele próprio um policial militar da reserva.

De acordo com o pronunciamento do juiz Marco Antônio Martins Vargas no dia 10 de agosto de 2005 , isto é, aproximadamente um ano após o 
incidente, havia passado para sete o número de policiais diretamente implicados no caso de Flávio Sant'Ana e que iriam a julgamento no mês seguinte. Contudo, o veredito só foi publicado no dia 19 de outubro daquele mesmo ano. Os dois policiais diretamente implicados no crime foram condenados a 17 anos e meio de prisão por homicídio duplamente qualificado, fraude processual e porte ilegal de armas. Os outros três cabos receberam penas menos longas por fraude processual e porte ilgeal de armas ou, simplesmente, por homício. O último dos sete policiais inicialmente acusados não foi julgado porque já havia falecido em um confronto armado. ${ }^{23}$

Quanto ao julgamento de Jean Charles de Menezes, o veredito divulgado pela corte da Independent Police Complaints Commission's (IPCC) no dia $1^{\circ}$ de novembro de 2007, a Polícia Metropolitana foi considerada "culpada por descumprimento da Lei de Segurança e Higiene no Trabalho". ${ }^{24}$ No entanto, várias circunstâncias em torno de sua morte e do procedimento policial empregado permanecem obscuras. Segundo a campanha lançada pela família da vítima e encampada pela Associação Fathers 4 Justice, ${ }^{25}$ nenhum dos policiais envolvidos no crime fizeram face individualmente a processo criminal ou a medida disciplinar. Além disso, relatório da Comissão de Denúncias Policiais Independentes (IPCC em inglês) permanece secreto e nenhuma satisfação foi dada à família sobre o intuito da Operação Kratos, que resultou na morte do jovem, nem quanto à discontinuidade da política de "atirar para matar".

\section{A estratégia de inculpar a vítima}

"Inculpar a vítima" parece ser a primeira estratégia de auto-defesa usa- da pela polícia em ambos os casos. No entanto, com o avanço das investigações, novas evidências foram trazidas à tona, reiluminando declarações anteriores. À medida em que os relatos das testemunha oculares foram sendo desacreditados, é interessante notar um novo procedimento sendo utilizado nos relatos da mídia: o divulgação de novas versōes dos fatos com base em documentos que "vazaram" do inquérito oficial.

O seguinte trecho foi retirado da edição online do jornal The Times do dia 17 de agosto e apresenta uma versão policial revista sobre a morte de Jean Charles:

\section{Sexta-feira, 22 de julho}

(...)

9h30: Policiais vêem [Jean Charles] de Menezes caminhar até uma parada de ônibus e embarcar em um veiculo que se dirigia à estação de metrô Stockwell. Ele está vestindo uma jaqueta jeans e não o casaco grosso acholchoado, capaz de esconder um cinto com explosivos, como havia sido dito inicialmente. Um guarda encarregado da vigilância de Tulse Hill examina as fotografias do suspeitos de terrorismo e decide que "valeria a pena se alguém fosse dar uma olhada" para verificar se o Sr. De Menezes conferia com elas. Ele próprio deixou escapar o momento em que De Menezes saía de casa, pois "eu [ele] estava me [se] preparando para partir", sendo, portanto, incapaz de transmitir suas observaçôes e ligar sua câmera de vídeo. Os policiais presumem que "a aparência e o comportamento" conferem com as de um dos suspeitos de terrorismo, dentre os quais estava Hussain Osman, acusado de ter bombardeado o Shepherd's Bush. O Gold Command [Divi-
23 "EXECUCÕ̃ES sumárias" Observatório das Violências Policiais: SP. São Paulo, out./2007. Disponível em: <http://www. ovp-sp.org/exec flavio santana.htm $>$. Acesso em: 24 out. 2007.

24 "REACTIONS to Menezes court verdict" BBC News. Londres, nov./2007. Disponível em: < http://news.bbc.co.uk/2/hi/uk news/7073347.stm >. Acesso em: 05 nov. 2007.

25 "LATEST news" The Jean Charles de Menezes Family Campaign. Londres, out./2007. Disponível em: < http://www. justice4jean.com/news.html>. Acesso em: 24 out. 2007. 
26 B00TH, Jenny "Timeline: The killing of Jean Charles de Menezes" Times Online. Londres, ago./2005. Disponível em: <http://www.timesonline.co.uk/tol/news/uk/ article556227.ece >. Acesso em: 17 ago. 2005.

27 PORFIRI0, Fernando. "Júri popular: PMs que mataram dentista negro vão a júri popular" Revista eletrônica: Consultor Jurídico. São Paulo, ago./2005. Disponível em: $<$ http://conjur.estadao.com.br/static/text/ 36475,1>. Acesso em: 18 ago. 2005. são Comando Dourado da policia de Londres] os instrui a impedir que De Menezes entrasse na estação (...)

10h: O filme da CCTV mostra

De Menezes entrando na estação, caminhando em ritmo normal, pegando um jornal gratuito do metrô e descendo vagarosamente a escada rolante. (...) Ao ouvir o trem se aproximando, ele cruza a plataforma correndo, entra no trem e se senta no primeiro assento vago. (...) Naquele momento, policiais armados foram "munidos de uma identificação positiva", segundo o documento.

Os policiais começam a gritar palavras de ordem como "policia". De Menezes se levanta e avança em direção dos policiais $d a$ CO19, de acordo com um dos guardas encarregados da vigilância.

Um outro membro da vigilância o agarra e o empurra de volta ao seu assento. "Eu agarrei o individuo de jaqueta jeans, envolvendo seu torso com meus dois braços, imobilizando suas mãos ao longo do corpo. Então eu o empurrei de volta ao assento em que ele estava sentado anteriormente... Eu então ouvi um disparo bem próximo do meu ouvido esquerdo e fui arrastado para o chão do vagão". 26

Passemos agora às últimas versões do caso de Flávio Ferreira Sant'Ana que estavam sendo veiculadas naquele mesmo momento. Em agosto de 2005, o jornal Estado de São Paulo relatava as últimas declarações da defesa dos policiais no julgamento dos assassinos de Flávio Sant'Ana:

"Os Policiais Militares insistiram na tese de que o dentista foi morto porque fez um movimen- to brusco durante a abordagem e não por ser negro. Em depoimento, afirmaram que, após deixarem o dentista no pronto-socorro do hospital Santana, seguiram ao $13^{\circ}$ Distrito Policial, onde apresentaram a versão falsa temendo "sançôes administrativas".

(...)

Cinco PMs já tinham assumido, em depoimento à Polícia Civil, que forjaram as provas do crime e omitiram informaçôes ao registrarem o boletim de ocorrência, mas negam que tenham agido movidos por racismo.

A estratégia da defesa do grupo é dizer que foi um homicídio culposo (sem intenção de matar). Além disso, segundo versão da defesa, três dos cinco PMs são negros (...).

O grupo diz que um dos soldados disparou contra o dentista porque, ao ser abordado pelos policiais, "ele [Flávio Sant'Ana] virou de forma brusca, fazendo entender que iria puxar uma arma".

O cabo Ricardo Arce Rivera disse que "plantou" a arma do crime junto ao dentista para simular resistência à prisão. Segundo a defesa, foi Rivera quem colocou a carteira do comerciante Antônio Alves dos Anjos no bolso do dentista-Anjos confundiu Sant'Ana com um assaltante".27

No caso da morte de Jean Charles, apesar de os meios pelos quais os policiais armados foram munidos de "identificação positiva" permanecerem ainda abertos a especulações, muito daquilo que fora inicialmente dito do seu "comportamento suspeito" acabou sendo colocado em dúvida. Contrariamente à morte de Flávio Sant'Ana, que aconteceu fora do alcance dos meios públicos de vigilância, o 
caso de Jean Charles conta com o benefício de uma outra fonte de evidências visuais: o filme da CCTV. Não obstante a falta de suporte visual no caso de Flávio Sant'Ana, a divulgação de informaçōes inéditas impôs a reelaboração de novas versôes dos fatos, reforçando a tese de que a polícia agiu com base no preconceito racial.

\section{De quem mais é a culpa?}

A declaração que se segue é atribuída ao pai de Flávio Ferreira Sant'Ana: "Se ele [seu filho] tivesse escrito 'eu sou dentista' em sua testa, hoje ele estaria vivo". 28 O que é mais desconcertante na declaração do pai de Flávio Sant'Ana é que ela sugere que não há nada de novo em ver negros ou qualquer pessoa de pele escura ser morto pelas forças policiais e que este é um procedimento comum. Além disso, ela sugere que parece haver somente uma saída para o padrão de tratamento dispensado às pessoas de cor: conquistar uma educação universitária. Se possível, dever-se-ia escrever esta "evidência” na própria testa.

A declaração do pai de Flávio Ferreira Sant'Ana é reforçada pelas estatísticas que foram divulgadas na ocasião do assassinato de seu filho: de acordo com um levantamento realizado pelo DataFolha, 91\% dos jovens negros entre 17 e 24 anos já foram abordados pela polícia. ${ }^{29}$ As estatísticas revelam ainda um crescimento no número de mortes cometidas por forças policiais - um aumento bastante preocupante, diga-se de passagem. Em 2001, a polícia de São Paulo foi responsável por 385 "autos de resistência" (termo usado para designar as mortes em supostos conflitos), ao passo que, em 2003, este número subiu para 868 - um aumento de aproximadamente $225 \%$. $^{30}$ Em 2005, o número de autos teria revelado 1.098 mortes, se levarmos em conta a totalidade do estado do Rio de Janeiro. ${ }^{31} \mathrm{Na}$ época da morte de Flávio Sant'Ana, a socióloga Julita Lemgruber, numa polêmica entrevista concedida à revista Época, exprime a mesma opiniāo do pai da vítima: "A maior vítima dessa violência policial é o pobre, preto, favelado", ${ }^{32}$ afirma. "A polícia diz que a maioria das pessoas morre em confrontos. Sabemos, e diversas pesquisas já indicaram isso, que, na maior parte dessas mortes, as pessoas levaram tiros pelas costas ou na cabeça". ${ }^{33}$ E conclui: "Fica evidente que não são mortes em confronto, são execuçōes". 34

Em um texto publicado no site do Observatório da Imprensa, em 17 de fevereiro de 2004,35 Alexandre Cruz Almeida levanta um outro aspecto intrigante: "por que a imprensa bate tanto na tecla de que ele era dentista", se Flávio Sant'Ana havia se formado apenas cinco dias antes de sua morte? Ao que ele responde: "Falemos sinceramente. O jornal está pendurado na banca, você está passando atrasado para o trabalho e vê de relance a manchete 'rapaz da periferia é morto por PMs'. Você pára para ler? Claro que não". Almeida argumenta que nem notícias como essa, nem outras tantas como "rapaz negro é morto por PMs” é merecedora de destaque na mídia. "O único modo de criar notícia é fazendo o rapaz parecer mais importante do que é. O que equivale dizer que sua importância intrínseca de ser humano, cidadão e filho não vale absolutamente nada". ${ }^{36}$

E se Jean Charles de Menezes tivesse escrito "eu sou brasileiro" na sua testa, estaria ele morto agora? Bem, provavelmente não. A decisão de "Sir" Ian Blair de manter a política de "atirar para matar", apesar da tragédia em questão, sugere que a morte de Jean Charles se encaixou perfeitamente nos seus planos de dar ao mundo uma demonstração exemplar da determinação do Reino Unido de combater o
28 ALMEIDA, Alexandre Cruz. "Morte de um dentista" Observatório da Impren-sa. Campinas, $n^{0} 264$, fev./2004. Disponível em: <http://observatorio.ultimosegundo. ig.com.br/artigos. asp?cod=264FDS003 > . Acesso em: 17 ago. 2005.

29 "UM ano sem 0 dentista Flávio. 0 quê mudou?" Portal Educafro. São Paulo, mar./2005. Disponível em: <http:// www. educafro.org.br/noticia/Infos/inform 050304.html> . Acesso em 10 ago. 2005.

30 "UMA polícia fatal" Centro de Estudos de Segurança e Cidadania. Rio de Janeiro, jan./2007. Disponível em: <http:// www.ucamcesec.com.br/md_part_texto. php?cod_proj=1>. Acesso em: $\overline{25}$ out. 2007.

${ }^{31}$ Idem.

32 COTES, Paloma. "Polícia sem controle" Revista Época. Riode Janeiro, $\mathrm{n}^{0} 300$, fev./2004. <http://revistaepoca.globo. com/Epoca/0,6993,EPT678129-1666,00. html> . Acesso em: 16 ago. 2005

${ }^{33}$ Idem.

34 Ibidem.

35 ALMEIDA, Alexandre Cruz. "Morte de um dentista" Observatório da Imprensa. Campinas, $n^{0}$ 264, fev./2004. Disponível em: <http://observatorio.ultimosegundo.ig.com.br/artigos.asp? cod = 264FDS003 >. Acesso em: 17 ago. 2005.

${ }^{36}$ Idem. 
37 HOLDEN, Michael. "Londres: deux autres suspects sont arrêtés" In: Le Devoir, «Le Monde». Montreal, jul./2005: p. 3.

38 HELENA, Eloisa. "Preto parado é suspeito e correndo é ladrao» Petição. Disponível em: < http://br.groups.yahoo.com/ group >. Acesso em: 03 ago. 2005. terrorismo. Além disso, ao menos durante o período que se seguiu imediatamente após a morte de Jean Charles, a opinião pública inglesa parecia apoiar as ações policiais e a política de "atirar para matar". Em uma pesquisa publicada três dias após o incidente, $71 \%$ dos cidadãos britânicos disseram apoiar o procedimento de atirar na cabeça, e não no torso ou em qualquer outro lugar, como forma de matar um suspeito de homem-bomba. ${ }^{37}$ Resta saber se eles ainda apoiariam tal procedimento à luz das novas evidências trazidas à tona durante a investigação da morte de Jean Charles.

Mas, o que seria de Jean Charles de Menezes se ele fosse realmente árabe? Este fato faria alguma diferença? Bem, talvez para uma classe média branca brasileira, que não está acostumada a ver a si mesma como um alvo racial potencial das forças policiais. Como argumenta a jornalista e militante negra Eloísa Helena: "A sociedade mundial está chocada com o assassinato do jovem brasileiro em Londres, e ignora o fato de que muitos 'Flávios' são executados diariamente sem serem dignos de uma manchete de jornal". ${ }^{38}$

De qualquer forma, o que parece evidente é que a política de "atirar para matar" tanto reforça como explicita os preconceitos raciais baseados em códigos visuais precisos de uma dada sociedade, códigos estes que são intrinsicamente contextuais e socialmente construídos. Mas qual o papel da mídia neste tipo de situação específica?

A mídia não é responsável pelos crimes em si, mas ela pode, certamente, infligir uma segunda forma de violência às vítimas. Ou seja, em casos em que a "evidência visível" associada ao crime não estava imediatamente disponível para o público (seja porque o crime aconteceu fora dos espaços expostos ao controle público e aos meios técnicos de gravação, como no caso de Flávio Sant'Ana; seja porque o acesso à tal informação foi altamente controlado pela polícia, como nos caso de Jean Charles), a mídia desempenha um papel ativo na conformação de uma "versão verossímel" daquilo que podeira ter ocorrido fora do alcance de suas câmeras. Neste sentido, as narrativas relativas ao assasinato de Jean Charles que foram apresentadas pela mídia inglesa, especialmente aquelas fornecidas pelas testemunhas oculares, estavam informadas pelo mesmo preconceito racial que motivou a ação policial.

Contudo, é importante notar que tanto Flávio Sant'Ana quanto Jean Charles eram o que se pode chamar de "vítimas erradas": o primeiro era um dentista recém-formado, filho de um policial reformado, ao passo que o segundo era um imigrante brasileiro, que não era nem árabe, nem muçulmano. Tais "evidências", apesar de não terem sido imediatamente captadas por seus respectivos algozes, acabaram sendo reveladas mais tarde pela mídia, forçando a polícia e a seus representantes à fornecerem novas explicações. A luz da informação que acabava de ser divulgada, a mídia passou a agir de modo mais reflexivo, vendose forçada a rever as narrativas que ela mesma havia divulgado anteriormente. Após ter sido confrontada ao seu próprio preconceito e ao preconceito de terceiros, a mídia foi capaz de promover o debate público, servindo como canal de reivindicação de mais visibilidade nos processos de apuração dos crimes em questão.

Para concluir, vale a pena registrar alguns comentários adicionais referentes à cobertura que a mídia brasileira fez de ambos os crimes. De maneira mais ampla, a morte de Jean Charles mereceu uma cobertura muito mais intensa e extensa do que a morte de Flávio Sant'Ana. Mas há uma outra diferença sutil entre os dois. Como foi 
sugerido pela própria versão do Comandante Geral da Polícia Militar do Estado de São Paulo à época da morte do jovem dentista, Flávio Sant'Ana foi morto em função da maneira como sua negritude foi percebida, isto é, como uma evidência visível de que se tratava de um ladrão ou de um bandido. Jean Charles, mesmo não sendo negro, constituiu um bom exemplo de de como determinados códigos fenotípicos podem variar conforme o contexto.

Minha intuição é de que a controvérsia em torno do assassinato deste último, assim como todos os protestos nacionalistas que ele levantou, foram consequências do fato de que, dentro do contexto brasileiro, Jean Charles tinha mais chances de ser considerado branco (ainda que porventura ele tenha uma ascendência africana nas últimas quatro gerações). Graças a este aspecto, a mídia brasileira foi muito mais proativa do que a inglesa, colocando os depoimentos oficiais em dúvida desde o primero instante. Mas o que parece ter finalmente escapado a muitos é que a mídia brasileira - a mesma mídia que luta contra a discriminação racial fora do país - parece ainda incapaz de perceber o quanto ela pode ser racista quando se trata de questôes nacionais.

\section{Abstract}

This paper focuses on the problem of racial profiling practices employed by police forces in Brazil and in England. In recent years, this very controversial method resulted in the death of two innocent Brazilian victims: Jean Charles de Menezes and Flavio Ferreira Sant'Ana. Because both events were the subject of intense media coverage in Brazil, comparative media analysis may provide valuable insight into the question of how crimes deriving from racist procedures call for specific media strategies. My main argument is that these two events - and the corresponding Brazilian public reactions they produced in Brazil and elsewhere - give expression to: 1) the problem of uncertainty inherent in any racial profiling system, especially in multicultural settings; 2) the contrastive Brazilian popular reactions and claims for justice in the cases above.

Key-words: media analysis, racial profiling, visibility, reflexivity, criminal reports.

\section{Referências}

ALMEIDA, Alexandre Cruz. "Morte de um dentista" Observatório da Imprensa. Campinas, no 264, fev./2004. Disponível em: <http://observatorio.ultimosegundo.ig.com.br/artigos.asp? $\operatorname{cod}=$ 264FDS003>. Acesso em: 17 ago. 2005.

BETTENCOUT, Babeth. "Morte de eletricista divide brasileiros em Londres" BBC News. Londres, jul./2005. Disponívelem:<http://www.bbc.co.uk/portuguese/reporterbbc/story/2005/07/050723reacaocomunidade.shtml>. Acesso em: 23 jul. 2005.

BLAIR discute mudança na lei anti-terrorismo com oposiçãa brintânica. BBC News. Londres, jul./2005. Diponível em: $<$ http://www.bbc.co.uk/portuguese/noticias/story/2005/07/050726-blairmeetsfn.shtml >. Acesso em: 26 jul. 2005.

BOMBER looked petrified. Sky News $T V$. Londres, jul./2005. Disponível em: <http://wwww.sky.com/skynews/article/00,30000'13391824,00.htm>. Acesso em: 23 jul. 2005.

BOOTH, Jenny. "Timeline: The killing of Jean Charles de Menezes" Times Online. Londres, ago./2005. Disponível em: <http://www.timesonline.co.uk/tol/ news/uk/article556227.ece>. Acesso em: 17 ago. 2005.

COMANDANTE diz que versão de PMs sobre morte de dentista é falsa. Folha Online. São Paulo, jul./2005. Disponível em: <http://wwwl.folha.uol.com.br/folha/ cotidiano/ult95u89837.shtml>. Acesso em: 27 jul. 2005. 
COTES, Paloma. Polícia sem controle. Revista Época. Riode Janeiro, no 300, fev./2004. Disponível em: <http://revistaepoca.globo.com/Epoca/0,6993, EPT678129-1666,00>.html. Acesso em: 16 ago. 2005.

EXECUÇÔES sumárias. Observatório das Violências Policiais: SP. São Paulo, out./2007. Disponível em: <http://www. ovp-sp.org/exec_flavio_santana.htm>. Acesso em: 24 out. 2007.

HELENA, Eloisa. Preto parado ésuspeito e correndo é ladrao. Petição. Disponível em: <http://br.groups.yahoo.com/group>. Acesso em: 03 ago. 2005.

JEAN Charles de Menezes. Wikipedia: a enciclopédia livre. Ago./2005. Disponível em: <http://en.wikipedia.org/wiki/Jean_ Charles_de_Menezes\#Controversy_over _police_procedure>. Acesso em: 15 ago. 2005.

LATEST news. The Jean Charles de Menezes Family Campaign. Londres, out./2007. Disponível em: <http://www.justice4jean.com/news.html>. Acesso em: 24 out. 2007.

MARTINS, Silvia Helena. "Racismo e violência" Mundo Negro: o maior portal da comunidade afro-brasileira. Ago./2005. Disponível em: <http:// www.mundonegro.com.br/noticias/index.php?noticiaID =265>. Acesso em: 15 ago. 2005.

PORFIRIO, Fernando. Júri popular: PMs que mataram dentista negro vão a júri popular. Revista eletrônica: Consultor Jurídico. São Paulo, ago./2005. Disponível em: <http://conjur.estadao.com.br/ static/text/ 36475,1>. Acesso em: 18 ago. 2005.

REACTIONS to Menezes court verdict" BBC News. Londres, nov./2007. Disponível em: <http://news.bbc.co.uk/2/hi/ uk_news/7073347.stm>. Acesso em: 05 nov. 2007.

SCOTLANDYardidentifiedeuxsuspects" Radio Canada. Montreal, jul./2005. Disponível em: <http://radio-canada.ca/nou- velles/acces/suite.asp?lien =/ nouvelles $/$ International/nouvelles/200507/24/001Londres-Ordre-Tuer.shtml>. Acesso em: 24 jul. 2005.

STOCK, Adriana; GARCEZ, Bruno. Brasileiro morto estava com visto vencido, diz governo. BBC News. Londres, jul./2005. Disponível em: <http://www. bbc.co.uk/portuguese/reporterbbc/ atory/2005/07/050723-alexricardoml. shtml>. Acesso em: 25 jul. 2005.

UM ano sem o dentista Flávio. O quê mudou? Portal Educafro. São Paulo, mar./2005. Disponível em: <http:// www. educafro.org.br/noticia/Infos/inform 050304.html>. Acesso em 10 ago. 2005.

UMA polícia fatal. Centro de Estudos de Segurança e Cidadania. Rio de Janeiro, jan./2007. Disponível em: <http:// www.ucamcesec.com.br/md_part_texto.php?cod_proj=1>. Acesso em: 25 out. 2007.

\section{Jornal}

HOLDEN, Michael. Londres: deux autres suspects sont arrêtés. In: Le Devoir, «Le Monde». Montreal, jul./2005: p. 3. 